\title{
Persistent embryonic right venous valve giving a cor triatriatum dexter appearance in a cyanotic neonate
}

\author{
Antonio J. Cartón, MD, ${ }^{\mathrm{a}}$ Álvaro González Rocafort, $\mathrm{MD}, \mathrm{PhD},{ }^{\mathrm{b}}$ Dolores Rubio, $\mathrm{MD},{ }^{\mathrm{a}}$ and \\ Luis García-Guereta, MD, PhD, ${ }^{\text {a }}$ Madrid, Spain
}

Embryonic right venous valve may persist after birth as a membrane seen inside the right atrium and give a cor triatriatum dexter appearance in echographic imaging. The finding is usually asymptomatic, but may rarely cause cyanosis when flow from the inferior vena cava is redirected into the left atrium and be misdiagnosed with a tricuspid valve anomaly. We report the case of a cyanotic newborn who underwent a successful resection of a cor triatriatum dexter membrane.

From the Departments of Pediatric Cardiology a and Pediatric Cardiovascular Surgery, ${ }^{\mathrm{b}}$ Hospital Universitario La Paz, Madrid, Spain.

Disclosures: Authors have nothing to disclose with regard to commercial support.

Received for publication May 29, 2011; revisions received June 26, 2011; accepted for publication July 14, 2011; available ahead of print Aug 8, 2011

Address for reprints: Álvaro González Rocafort, MD, PhD, Hospital Universitario La Paz, Paseo de la Castellana 261, 28046 Madrid, Spain (E-mail: algonroc@hotmail. com).

J Thorac Cardiovasc Surg 2011;142:e147-8

$0022-5223 / \$ 36.00$

Copyright (C) 2011 by The American Association for Thoracic Surgery doi:10.1016/j.jtcvs.2011.07.023

\section{CLINICAL SUMMARY}

A cyanotic male neonate was assessed because of suspicion of congenital heart disease. At 48 hours after birth, he demonstrated central cyanosis that was unresponsive to oxygen administration and required hospital admission at another center. At first evaluation, a diagnosis was made of dysplastic tricuspid valve not meeting Ebstein anomaly criteria; a prostaglandin $\mathrm{E}_{1}$ infusion was started, and he was transferred to our institution. On admission, his saturation values remained under $85 \%$ despite patency and adequate ductal size. Chest radiography showed signs of relative pulmonary ischemia. In 2-dimensional echocardiography, a supratricuspid ring was detected in the 4-chamber view; in subcostal projections, however, a highly moving membrane dependent on the Eustachian valve was identified. A transtricuspid, nonobstructive, low-flow pattern was noted, with the flow from the inferior vena cava being diverted through the patent foramen ovale to the left atrium (Figure 1). A quick filling of the left atrium after
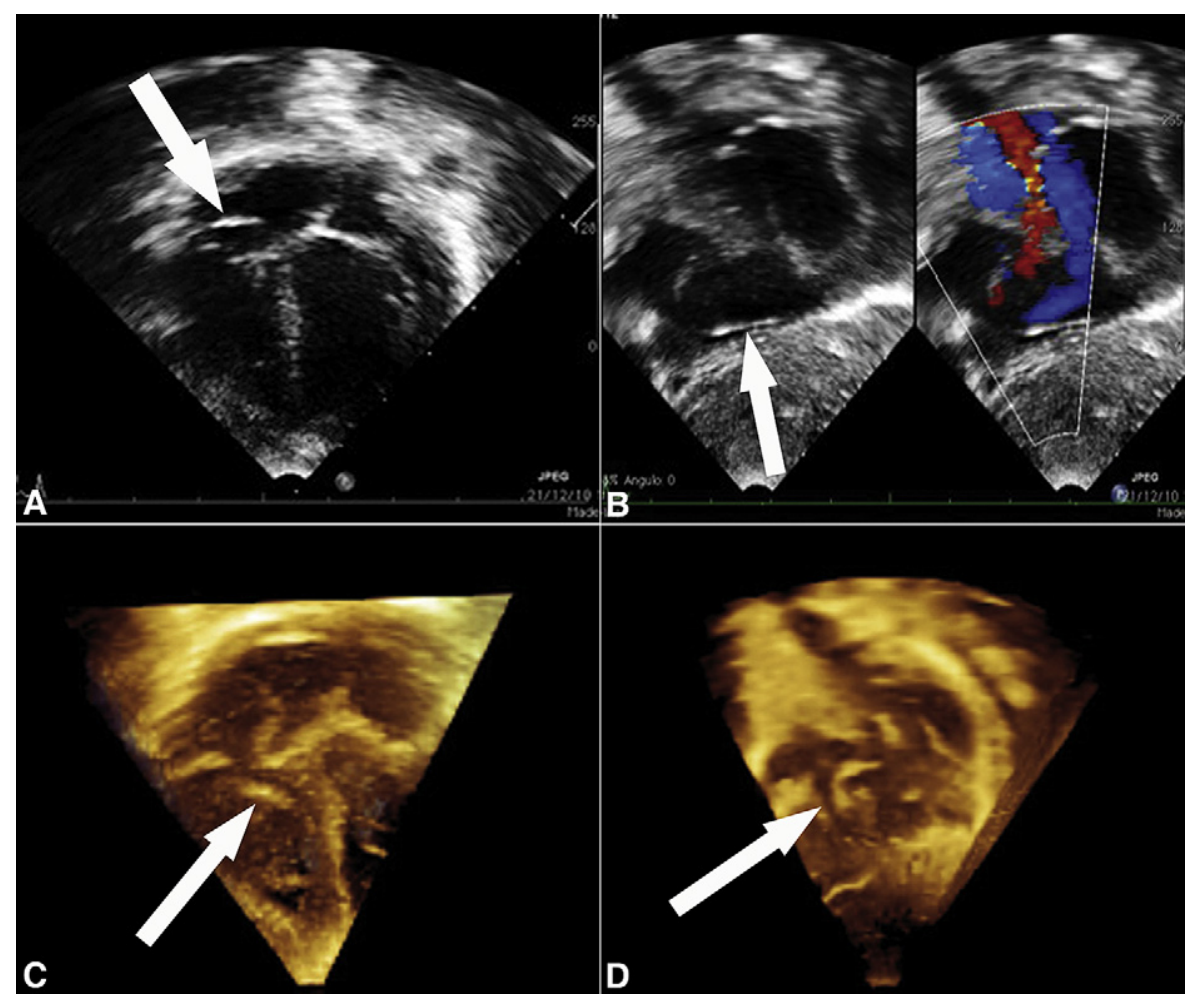

FIGURE 1. A, Four-chamber view. A ring-shaped membrane is seen beside the tricuspid valve (arrow). B, Subcostal short-axis view. A membrane intruding in the tricuspid valve is seen on the left (arrow). On the right, blue pattern shows flow from the inferior vena cava to the left atrium; red pattern is the flow from the superior vena cava. $\mathrm{C}$ and $\mathrm{D}$, Three-dimensional echocardiographic images showing the membrane (arrows). 


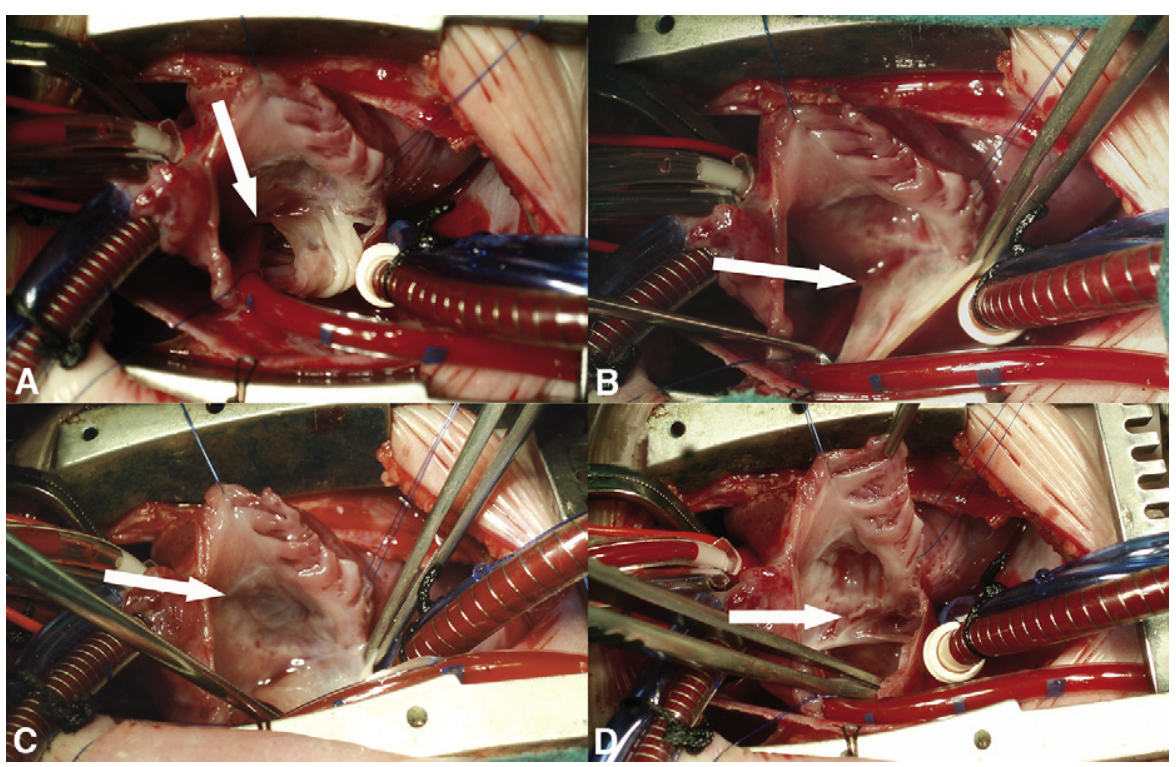

FIGURE 2. A, Persistent foramen ovale with a vent (arrow) covered by the membrane. B, The persistent embryonic right venous valve seen through right atriotomy (arrow). C, Competent tricuspid valve (arrow) and its relation with the membrane. D, After resection of the membrane (arrow), the sinus venosus is shown.

administration of rough saline suspension in a peripheral lower limb vein was evidenced (not shown). Threedimensional echocardiography supported the suspicion of persistence of the embryonic right venous valve, giving the appearance of a cor triatriatum dexter. In the ensuing days, an increase in oxygen saturations up to $90 \%$ to $92 \%$ was seen in correspondence with an improvement in the vascularity pattern of the lungs. Images were later obtained in the operating room and confirmed the echocardiographic diagnosis (Figure 2). The recovery of the baby was uneventful.

\section{DISCUSSION}

The term cor triatriatum usually refers to a rare congenital defect consisting of a left atrium divided by a membrane to create 2 chambers, a proximal chamber that receives the 4 pulmonary veins and a distal chamber that is connected to the mitral valve (cor triatriatum sinister). Cor triatriatum dexter is an even rarer congenital anomaly. ${ }^{1,2}$ The membrane dividing the right atrium is usually a remnant of the embryonic right venous valve, one of the valvular folds bordering on the connection between the sinus venosus and the embryologic right atrium; the left fold of this membrane results in a part of the septum secundum. During fetal life, the valve redirects the enriched oxygen flow from the inferior vena cava to the left atrium through the patent foramen ovale. ${ }^{3}$

Abnormal persistence of the embryonic right venous valve is usually asymptomatic when a mild, nonobstructive structure is present and is casually diagnosed in adult life or in autopsy examinations. More severe forms may cause obstruction to the flow either from the inferior vena cava or to the tricuspid valve. The membrane may even introduce itself into the right ventricular outflow tract, causing extreme hemodynamic instability.

Surgical resection is warranted when symptoms of flow obstruction or desaturation appear. Although there have been reported cases of successful percutaneous transluminal approaches, the surgical technique is straightforward.

Cardiac surgery is performed under cardiopulmonary bypass, either with mild hypothermia or with normothermia. The right atrium is opened, and the membrane is visualized, usually arising between the septal leaflet of the tricuspid valve and the sinus venosus. Careful detachment of the membrane is accomplished, avoiding damage to the conduction system. The postoperative course is not risky, and symptomatic improvement occurs right after cardiopulmonary bypass.

In our case, it is likely that persistent pulmonary hypertension exacerbated the cyanosis. Right-to-left shunting across the patent foramen ovale explains the basal desaturation unresponsive to oxygen administration. Aberrations of the tricuspid valve, including Ebstein anomaly, may mislead the diagnosis. ${ }^{4}$ Surgical resection is warranted when persistent desaturation is observed.

\section{References}

1. Barrea C, Rubay J, Wagner K, Ovaert C. Images in cardiovascular medicine: cor triatriatum dexter mimicking Ebstein disease. Circulation. 2009;120:e86-8.

2. Galli MA, Galletti L, Schena F, Salvini L, Mosca F, Danzi GB. A rare case of neonatal cyanosis due 'cor triatriatum dexter' and a review of the literature. J Cardiovasc Med (Hagerstown). 2009;10:535-8.

3. Hoye DJ, Wilson EC, Fyfe DA, Guzzetta NA. Cor triatriatum dexter: a rare cause of neonatal cyanosis. Anesth Analg. 2010;110:716-8.

4. Salam S, Gallacher D, Uzun O. Cor triatriatum dexter masquerading as Ebstein's anomaly. Cardiol Young. 2011;4:1-3. 